\title{
Acesso e permanência estudantil na Universidade Federal da Fronteira Sul Campus Realeza/PR
}

\author{
Student access and permanence at the Universidade Federal da Fronteira Sul \\ Campus Realeza/Paraná/Brazil
}

\begin{abstract}
${ }^{1}$ Aline Juliana Scher - Universidade Estadual do Oeste do Paraná | Toledo | PR | Brasil. E-mail: linejuly@gmail.com. ORCID: http://orcid.org/0000-0003-4259-7581

${ }^{2}$ Edson Marques Oliveira - Universidade Estadual do Oeste do Paraná | Toledo | PR | Brasil. Email: coacholiveira@hotmail.com. ORCID: http://orcid.org/0000-0001-9363-7358
\end{abstract}

Resumo: Nos últimos anos temos assistido a expansão do Ensino Superior no Brasil, seja por meio da criação ou ampliação de Universidades e Institutos Federais ou pelo incentivo e financiamento de bolsas em instituições particulares. Com isso, o número de vagas cresceu de forma significativa, possibilitando o acesso à educação superior para um número maior de brasileiros. Aliado à expansão, algumas mudanças na legislação propiciaram a abertura de vagas para estudantes das camadas mais populares da sociedade, historicamente excluídas do modelo elitista da educação superior pública brasileira. Nesse contexto, ampliar o acesso é elementar para a democratização do ensino superior, contudo outros desafios se apresentam para garantir de fato a inclusão deste público. É neste debate que pretendemos contribuir ao apresentar os resultados de uma investigação realizada em um campus da Universidade Federal da Fronteira Sul, localizado no interior do Paraná.

Palavras-chave: Ensino superior. Acesso e permanência. Assistência estudantil.

Abstract: In the last years, it have been seen the expansion of higher education in Brazil, either through creation and amplification of universities and federal institutes or by the encouragement and funding scholarship in private institutions. With that, the number of vacancies increased significantly, permitting that more Brazilians have access to higher education. Furthermore, some changes in the legislation allowed the opening of vacancies for students from the most popular level of the society, which are historically excluded from the elitist model of Brazilian public higher education. In this context, to amplify the access is essential for higher education democratization, although there are other challenges arising in order to assure the inclusion of this popular public. It's in that debate that we intend to contribute by presenting the results of the research carried out on the campus of the Federal University of Fronteira Sul, located in the interior of Paraná - Brazil.

Keywords: Higher education. Access and permanence. Student assistance.

Recebido em: 26 de novembro de 2017

Aprovado em: 28 de fevereiro de 2020

DOI: http://dx.doi.org/10.1590/S1414-40772020000100002

Este é um artigo publicado em acesso aberto sob uma licença Creative Commons

https://creativecommons.org/licenses/by-nc/4.0/ 


\section{Introdução}

Neste artigo propomo-nos a discutir o binômio acesso/permanência no Ensino Superior. A investigação teve como objetivo analisar se após o acesso à Universidade, os programas de Assistência estudantil têm conseguido garantir a permanência e a conclusão de curso dos acadêmicos. Trata-se de um estudo de caso, com uso das técnicas de pesquisa bibliográfica e documental, que analisou dados da Universidade Federal da Fronteira Sul - UFFS Campus Realeza-PR. $^{1}$

Desse modo, o tema central que permeia o presente artigo é a política de assistência estudantil que tem a finalidade de possibilitar a permanência dos estudantes que acessam os cursos nas Instituições Federais de Ensino Superior (IFES). O recorte que fizemos é com enfoque no caso específico da permanência dos acadêmicos do Campus da UFFS em Realeza, no Paraná.

A investigação realizada permitiu analisar a assistência estudantil e sua relação com os índices de permanência e conclusão de curso, observando os reflexos das ações implementadas com estudantes atendidos e que apresentam vulnerabilidade socioeconômica. Assim, o problema que moveu a pesquisa foi o seguinte: Considerando a criação do Programa Nacional de Assistência estudantil como um mecanismo de política social, inserido na Política de Educação Superior pública no Brasil, com o objetivo de minimizar os efeitos das desigualdades sociais e regionais na permanência e conclusão da educação superior e reduzir as taxas de retenção e evasão, perguntase: em que medida a assistência estudantil implementada na UFFS a partir de 2010, tem possibilitado, para além do acesso, a permanência e a conclusão de curso dos estudantes no Campus Realeza-PR?

Para responder a esta pergunta analisamos os documentos internos da Universidade, como relatórios, editais e históricos escolares. A documentação do universo de participantes dos programas de assistência no Campus Realeza foi pesquisada, totalizando 572 (quinhentos e setenta e dois) estudantes que estiveram inseridos nos programas de auxílios socioeconômicos entre 2010 e 2016. A trajetória acadêmica no curso e a participação destes estudantes nos programas foram analisadas e o tratamento estatístico permitiu o cruzamento de dados e a elaboração de gráficos e relatórios. Portanto, ao abordar neste artigo a temática do acesso e permanência no Ensino Superior,

\footnotetext{
1 A pesquisa foi realizada durante os estudos no Programa de Mestrado em Serviço Social, desenvolvido na Universidade Estadual do Oeste do Paraná - Unioeste.
} 
vamos apresentar os principais resultados alcançados na investigação realizada. Todavia, inicialmente pretendemos tecer algumas considerações a respeito da temática em estudo.

\section{A Política de Educação Superior Pública Brasileira e suas configurações atuais}

O Brasil é um país de índices desproporcionais no que diz respeito à distribuição e socialização das riquezas produzidas. Os dados comprovam esta afirmação mostrando o quanto o Brasil é um espaço constituído por algumas "ilhas" de riqueza que são rodeadas por um "mar" da pobreza. De acordo com estudos do IBGE (BRASIL, 2014), em 2013 as pessoas com os 10\% menores rendimentos concentravam apenas $1,2 \%$ da renda total. $\mathrm{O}$ décimo por cento mais rico concentrou durante todo o período analisado mais de $40 \%$ da totalidade da renda per capita brasileira.

Essa realidade gera debate sobre a necessidade de se construir mecanismos que promovam equilíbrio entre o desenvolvimento humano e a geração de riquezas. Nesse sentido, o Brasil buscou mudar estes indicadores implementando políticas públicas em diversas áreas na tentativa de reduzir essa desigualdade, incluindo nesse contexto as mudanças na política educacional do ensino superior, ampliando a criação de Universidades e Institutos federais no país especialmente entre os anos de 2003 e 2014.

Florestan Fernandes (1975) aponta que a Universidade Brasileira lançou suas raízes históricas, culturais e pedagógicas em modelos institucionais europeus, resumindo-se de início a uma única função: a de preparar um grupo letrado apto para o exercício de profissões liberais. Desse modo, o ensino superior brasileiro nasceu com esse caráter colonialista, dependente e classista. Em face disso, a Educação Superior estabeleceu historicamente bases elitistas e se consolidou como um local privilegiado para a (re)produção das elites econômicas do país.

$\mathrm{Na}$ história recente do Brasil essa realidade começou a sofrer algumas mudanças. Conforme destaca Oliveira (2009),

Pode-se considerar que no decorrer desses dois mandatos do presidente Lula houve iniciativas importantes do ponto de vista de políticas regulares de educação no sentido de buscar recuperar o papel protagonista do Estado federal como promotor de políticas para o setor, bem como de tentativas de correção de distorções naturais de um país com as dimensões do Brasil e com suas diferenças regionais (OLIVEIRA, 2009, p. 207). 
Na Educação Superior durante o governo Lula, consideramos como parte fundamental e integrante do objeto de nossa análise as ações relacionadas à ampliação do acesso à educação superior. Assim, neste artigo, vamos dar ênfase ao processo de criação e interiorização de novas IFES, abertura de novas vagas, expansão do acesso, bem como a permanência estudantil.

No que se refere a expansão das vagas das universidades públicas federais, no interior das quais se estruturam os programas de assistência estudantil, o governo Lula teve como principal ação a consolidação do Programa de Apoio a Planos de Reestruturação e Expansão das Universidades Federais - o REUNI (BRASIL, 2007). Este Programa assumiu como principais diretrizes: a redução das taxas de evasão; ocupação de vagas ociosas e aumento de vagas de ingresso, especialmente no período noturno; ampliação da mobilidade estudantil; reestruturações curriculares; ampliação de políticas de inclusão e assistência estudantil, entre outros.

Os desdobramentos do REUNI contemplaram repasses financeiros às instituições que já existiam e a criação de novas Instituições Federais. Na primeira fase de expansão, mais de 60 (sessenta) campus do interior e 10 (dez) Universidades foram criadas, sendo 6 (seis) dessas criadas por transformação, isto é, unidades (campus, faculdade, escola) foram transformadas em Universidades. Com a continuidade nas ações de expansão das Universidades Federais, no total foram criados 115 (cento e quinze) novos campi no interior e 14 (quatorze) universidades. (BRASIL. MEC, 2008). É nesse âmbito que se situa a Universidade Federal da Fronteira Sul, que foi criada com recursos advindos do REUNI.

A expansão das Universidades Federais ocorreu, em sua maioria, por meio da interiorização das instituições. Segundo dados do Instituto de Pesquisa Econômica Aplicada (IPEA), o processo de interiorização promovido pelo REUNI mediante a criação de novos campi, sejam estes vinculados aos Institutos Federais de Educação Tecnológica ou às Universidades, resultou num aumento das matrículas nas unidades de ensino localizadas no interior, que passou de 35,6\% em 2007 para 47,7\% em 2012 (BRASIL, 2014a).

A inserção da assistência estudantil enquanto uma das diretrizes do REUNI teve impacto direto na elaboração e reconhecimento do Plano Nacional de Assistência Estudantil, formulado no ano de 2007 pelo Fórum Nacional de Pró-Reitores de Assuntos Comunitários e Estudantis (FONAPRACE) e, na sua posterior institucionalização pelo Decreto Federal $n^{\circ} 7.234$, de 19 de julho de 2010, que cria o Programa Nacional de Assistência Estudantil (PNAES). 
É relevante destacar que a Assistência Estudantil percorreu no Brasil uma longa trajetória para alcançar o reconhecimento do poder público. Segundo Kowalski (2012), o cenário de origem das primeiras ações de assistência assinala sua construção por meio de um processo descontínuo, com avanços e retrocessos, sendo subordinada a configuração do Estado em cada momento histórico.

Somente na década de 1980 que a discussão sobre a permanência estudantil passa a ganhar mais concretude. Os problemas decorrentes do acesso e permanência na educação superior ganham espaço para ser discutidos nos Encontros Nacionais de Pró-Reitores de Assuntos Comunitários e Estudantis e nas reuniões realizadas pela Associação Nacional dos Dirigentes das Instituições Federais de Ensino Superior (ANDIFES). Esses espaços de discussões criaram condição para ser instituído, em 1987, o Fórum Nacional de Pró-Reitores de Assuntos Comunitários e Estudantis (FONAPRACE), que congrega Pró-Reitores e Responsáveis pelos assuntos comunitários e estudantis das IFES do Brasil (ANDIFES, 2012) ${ }^{2}$, que na busca pelo estabelecimento de uma política nacional dirigida à comunidade universitária, aprofundou as discussões e ações na sistematização de uma proposta de política de assistência ao estudante que garantisse acesso, permanência e conclusão de curso nas IFES (KOWALSKI, 2012).

Nessa trajetória, a assistência estudantil passa mesmo a ter maior notoriedade somente a partir dos anos 2000 com a atenção dada pelo governo à expansão do ensino superior. É no contexto da aprovação do REUNI com o Decreto n ${ }^{\circ}$ 6.096, de 24 de abril de 2007, que é previsto legalmente a criação de mecanismos que possibilitem a ampliação do acesso e permanência na educação superior, no nível de graduação. Como diretrizes, destaca-se no artigo $2^{\circ}$, item II deste Decreto, a ampliação de políticas de inclusão e de assistência estudantil.

As pesquisas aplicadas pelo FONAPRACE nos anos de 1997 e 2004 mapearam a realidade nacional das universidades federais, possibilitando diagnosticar a situação dos estudantes matriculados. Esse diagnóstico permitiu a elaboração do Plano Nacional de Assistência Estudantil

${ }^{2}$ O Fórum Nacional de Pró-Reitores de Assuntos Comunitários e Estudantis - FONAPRACE é órgão assessor da Associação Nacional dos Dirigentes das Instituições Federais de Ensino Superior - ANDIFES. Criado em 1987 com a finalidade de promover a integração regional e nacional das Instituições de Ensino Superior (IES) Públicas visando fortalecer as políticas de Assistência ao Estudante. O FONAPRACE objetiva: garantir a igualdade de oportunidades aos estudantes das IES Públicas na perspectiva do direito social; proporcionar aos alunos as condições básicas para sua permanência na Instituição; assegurar aos estudantes os meios necessários ao pleno desempenho acadêmico; contribuir na melhoria do Sistema Universitário, prevenindo e erradicando a retenção e a evasão escolar, quando decorrentes de dificuldades socioeconômicas (p. 103). 
que identificou as dificuldades socioeconômicas de uma parcela significativa do segmento estudantil como uma das causas da evasão e da retenção. Segundo o Fórum, questões como moradia, alimentação, manutenção, meios de transporte e saúde são algumas das demandas primordiais para garantir a permanência desses estudantes nas IFES. Assim, o Plano Nacional de Assistência Estudantil, elaborado pelo FONAPRACE em 2007, apresenta as diretrizes norteadoras para a definição de programas e projetos dessa natureza (ANDIFES, 2007).

Desse modo, após longa trajetória histórica, a assistência estudantil finalmente passa a ter reconhecimento. É aprovado, em 2007, o Programa Nacional de Assistência Estudantil - PNAES pela Portaria Normativa $n^{\text {o }} 39$ do MEC, de 12 de dezembro de 2007 (BRASIL, 2007a). Não obstante, apenas a partir de 2008 é que o poder público, atendendo as antigas reivindicações das IFES e dos movimentos estudantis, passou a destinar recursos orçamentários para a assistência estudantil, sendo que em 19 de julho de 2010, o ex-presidente Lula transformou o Programa em Decreto de $n^{\circ}$ 7.234/2010 (BRASIL, 2010).

Esse Decreto federal estabelece no Art.4º parágrafo único, que as ações desenvolvidas no âmbito da assistência estudantil "[...] devem considerar a necessidade de viabilizar a igualdade de oportunidades, contribuir para a melhoria do desempenho acadêmico e agir, preventivamente, nas situações de retenção e evasão decorrentes da insuficiência de condições financeiras." (BRASIL, 2010).

Portanto, a assistência estudantil aparece na agenda governamental - inclusive com significativa dotação orçamentária - vinculada ao controle das elevadas taxas de evasão e retenção universitária. Esses índices são empecilhos para materialização das propostas "democratizantes" da universidade pública, sobretudo por reduzir a "eficiência" do sistema público, pois aumentam os gastos do governo federal e impedem a liberação das vagas para outros estudantes, fatores estes que distanciam o governo do alcance da meta de $90 \%$ de taxa de conclusão de curso.

De fato, é necessário reconhecer que a evasão e retenção podem ter relação com questões de ordem financeira, como a ausência de recursos para se manter ou a necessidade de trabalho por parte do estudante, para a subsistência dele e de seus familiares. Nesse cenário, a assistência financeira tende a contribuir para auxiliar aqueles indivíduos que provêm de famílias de baixo poder aquisitivo. Contudo, é preciso observar que as situações de evasão passam também por inúmeros outros condicionantes que podem interferir no processo de formação acadêmica. 
Entendemos, fundamentados em nossa pesquisa, que para a ampliação e expansão de vagas resultar efetivamente em um processo de inclusão social, de fato democratizante, é necessário garantir, além do acesso ao ensino superior público, uma política pública sólida e contínua voltada à permanência e apoio à formação integral de qualidade dos sujeitos sociais que ingressam na Universidade. Esse assunto se faz presente na análise que passaremos a expor na sequência, acerca da investigação realizada.

\section{Acesso e Permanência na Universidade Federal da Fronteira Sul - Campus Realeza}

A Universidade Federal da Fronteira Sul (UFFS) foi criada em 2009 no contexto do REUNI e instituída com base nos preceitos da política nacional de expansão e interiorização da educação superior. A UFFS está localizada na Mesorregião Grande Fronteira do Mercosul, abrangendo cerca de 400 (quatrocentos) municípios nos três estados da região Sul do Brasil. É uma Instituição multicampi, criada inicialmente com cinco campus: dois no Sudoeste do Paraná (Campus Laranjeiras do Sul e Realeza), um no Oeste de Santa Catarina (Campus Chapecó, onde também está localizada a Reitoria) e dois no Noroeste do Rio Grande do Sul (Campus Erechim e Cerro Largo). O Campus Passo Fundo foi criado posteriormente, no ano de 2013, quando iniciou seu funcionamento com o curso de graduação em Medicina autorizado pelo MEC por meio da Portaria

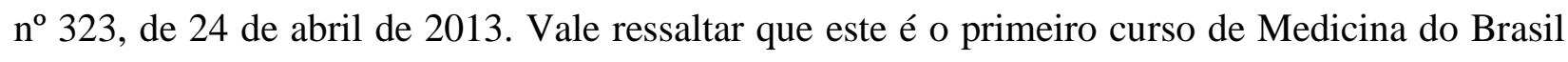
instituído através do programa de expansão das escolas médicas do Governo Federal (UFFS, 2017a).

A UFFS foi criada com o intuito de contribuir para a formação humana crítica, o desenvolvimento regional e a inclusão social, combatendo as desigualdades sociais e regionais. Teve forte protagonismo dos Movimentos Sociais em seu processo de criação, com debates, mobilizações e negociações que ocorreram, inicialmente, de forma isolada nos três estados do Sul do país. A partir de 2005 as diversas frentes de reivindicação articularam-se e criaram o chamado Movimento Pró-Universidade, que reuniu movimentos populares das regiões sudoeste do Paraná, oeste de Santa Catarina e norte do Rio Grande do Sul, todos movidos pelo mesmo objetivo: criar uma Universidade Federal nesta região. (UFFS, 2017a)

Portanto, a UFFS é uma instituição de ensino superior pública, criada pela Lei Federal n ${ }^{\circ}$ 12.029, de 15 de setembro de 2009. Caracteriza-se como uma autarquia federal, vinculada ao 
Ministério da Educação (MEC), com autonomia didático-científica, administrativa, de gestão patrimonial e financeira, nos termos da sua Lei de criação e de seu Estatuto (UFFS, 2013).

A partir desse histórico de criação, é necessário destacar uma importante diferenciação entre a UFFS e as demais universidades brasileiras:

A UFFS foi a primeira universidade pública federal cuja criação deveu-se, diretamente, ao poder de mobilização e de convencimento público pelos movimentos sociais e pelas lideranças políticas e comunitárias. As redes de associativismo civil e o denso tecido de organizações sociais da região - berço de alguns dos principais movimentos sociais do campo do Brasil - foram mobilizados para a formulação do projeto de universidade e sua subsequente concretização (ROMÃO; LOSS, 2014, p. 150).

Romão e Loss (2014, p. 150), enfatizam ainda que o movimento de criação se "[...] orientou pela construção de uma IES pública e popular, aberta aos grupos sociais mais excluídos e comprometida com o desenvolvimento sustentável e solidário da região [...]".

Em relação aos primeiros estudantes ingressantes na UFFS em março de 2010, Rotta, Vitcel e Andrioli (2012, p. 61-62) destacam alguns números que caracterizam o seu perfil: “[...] 79\% não cursaram pré-vestibular; $87 \%$ são oriundos de famílias com renda de até cinco salários mínimos; em sua maioria são trabalhadores assalariados; e 87\% representam a primeira geração da família a chegar a um curso universitário". Segundo os autores, o percentual de estudantes da UFFS egressos da escola pública foi de 93,68\%, e no ano de 2011 foi ainda superior, chegou a 95,55\%.

Em matéria publicada no sítio eletrônico da UFFS, em fevereiro de 2010, o então Reitor pró-tempore, professor Dilvo Ristoff, analisa o perfil dos estudantes que ingressaram e faz a seguinte menção:

Estamos construindo uma universidade pública de acordo com a lógica da paridade entre as matrículas do ensino médio público e do ensino superior público, pois $89 \%$ do ensino médio brasileiro é público. [...] Como esta paridade pode ser observada em todos os cursos da instituição, constata-se que a UFFS altera a lógica, historicamente tão criticada, que fazia com que na maioria dos cursos da IES públicas e gratuitas, especialmente nos cursos mais disputados, os alunos fossem oriundos das escolas privadas e pagas (UFFS, 2010).

Podemos verificar diante disso que a Universidade Federal da Fronteira Sul - por seu histórico de criação que envolveu movimentos populares; por sua proposta inovadora destacada em seus documentos institucionais como pública e popular; e por meio de sua política de ingresso que reserva cerca de $90 \%$ das vagas na graduação para estudantes que cursaram o ensino médio 
exclusivamente em escola pública - configura-se como uma IFES ímpar, que se diferencia em alguns aspectos das demais Universidades Federais.

O Campus Realeza ${ }^{3}$, que está localizado na região sudoeste do Paraná, oferta seis cursos de graduação, dos quais quatro são licenciaturas (Letras-Português/Espanhol, Ciências Biológicas, Química e Física) e dois são bacharelados (Nutrição e Medicina Veterinária). Todos os cursos do campus ofertam um ingresso anual, sempre no primeiro semestre de cada ano letivo. As licenciaturas concentram-se no período noturno e os cursos de bacharelados ocorrem em período integral (manhã e tarde).

Em 2016, ano de realização desta pesquisa, o quantitativo de matrículas ativas chegou a 800 (oitocentos) acadêmicos em Realeza, dos quais 708 (setecentos e oito) estudantes eram oriundos do estado do Paraná e, em sua grande maioria, dos municípios que compõe a Microrregião integrada por Realeza. Os demais estados com maior número de acadêmicos foram Santa Catarina e São Paulo, seguido por Rio Grande do Sul. Outro dado muito relevante aponta que do total de acadêmicos ativos no campus em 2016, apenas 32 (trinta e dois) não cursaram o Ensino Médio em escola pública. (UFFS, 2017b). Estes elementos sugerem que a Universidade pode estar atingindo o princípio primário para o qual foi criada, atendendo o público, em sua maioria, desta região e um grupo social oriundo de escola pública, dos quais poucos provavelmente teriam acesso ao Ensino superior se não fosse gratuito e ofertado na região.

O Campus Realeza abre anualmente em média 220 (duzentas e vinte) vagas pelo Processo seletivo regular para novos ingressantes nos cursos de graduação ${ }^{4}$. Além destas, há a abertura de vagas por Processos seletivos especiais, como o Programa de Acesso e Permanência dos Povos Indígenas (PIN) e o Programa de Acesso à Educação Superior da UFFS para Estudantes Haitianos (PROHAITI). O Campus ofertou também em 2016, dois cursos de pós-graduação latu sensu, sendo um deles em Direitos Humanos e o outro na área de Ciências Naturais e Sociedade. Além disso, em 2017 teve a abertura do seu primeiro Mestrado na área de Saúde, Bem-estar animal e Produção animal sustentável na Fronteira Sul.

3 O município de Realeza, em conjunto com outros sete municípios, integra a Microrregião de Capanema no Sudoeste do Estado do Paraná. Localiza-se a 523 quilômetros da capital - Curitiba. Tem população estimada, em 2016, de 17.068 habitantes. A principal fonte de renda do município provém da produção agropecuária. Realeza foi um dos locais que se habilitou para receber um Campus da UFFS o que se seguiu uma serie de procedimentos.

4 Mais detalhes sobre cada curso e a política de ingresso poderão ser consultados na página institucional da UFFS na internet: www.uffs.edu.br 
Desde o primeiro Processo Seletivo para o ingresso na graduação a UFFS não utiliza os tradicionais vestibulares. A Instituição optou pela utilização do Exame Nacional do Ensino Médio (ENEM) como prova de conhecimentos básicos para o ingresso na Universidade. Nos Processos seletivos dos anos de 2010, 2011 e 2012 utilizou uma política criada internamente, denominada como "Fator Escola Pública", que consistia em um acréscimo à nota dos candidatos no ENEM com base no número de anos que cursou o ensino médio em escola pública. Em síntese, o candidato recebia uma bonificação de 10\% sobre sua nota do ENEM para cada ano cursado em escola pública. Assim, o estudante que cursou todo o ensino médio em escola pública teve um bônus de $30 \%$ acrescido à sua nota final do ENEM (PEREIRA, 2015). O candidato selecionado para matrícula comprovava então, por meio do histórico escolar, que efetivamente cursou em escola pública o número de anos declarado no ato da inscrição.

A adoção do Fator Escola Pública só deixou de ser aplicado pela UFFS no Processo seletivo de 2013, devido à promulgação da Lei Federal n 12.711 , em agosto de 2012, que dispõe sobre o ingresso nas IFES. A lei ficou conhecida como Lei de Cotas. A UFFS então adequou de imediato seu modelo de ingresso integralmente conforme a nova lei, o que não afetou a priorização do acesso aos candidatos de escola pública, pois esta já era uma ação adotada desde o primeiro processo seletivo da UFFS.

Atualmente sua reserva de vagas para escola pública supera consideravelmente os $50 \%$ exigidos por lei, pois a instituição adotou como critério de reserva o mesmo percentual de estudantes que concluem o ensino médio na escola pública, conforme o último censo da educação básica de cada ano e para cada Estado em que estão localizados os campi da Instituição. Além disso, a UFFS criou também outras ações afirmativas de acesso para indígenas, haitianos e estudantes que frequentaram parcialmente a escola pública.

Diante desse contexto, no que tange ao acesso, é perceptível que esta Universidade vem cumprindo um importante papel para a garantia da democratização do acesso ao Ensino Superior. Sua política de ingresso é um fator decisivo para o alcance dessa democratização às camadas sociais mais populares antes excluídas da educação superior.

Entendemos que a democratização do acesso, não apenas na UFFS, mas na educação superior federal como um todo a partir da aprovação da "Lei das cotas", é fundamental para uma sociedade democrática que estabelece em sua Carta Magna o direito à educação. Porém, compreendemos também que o acesso ao ensino superior não é suficiente para dar conta da redução 
das grandes desigualdades existentes. Outro elemento necessário é uma consistente política de permanência e incentivo à conclusão do curso, voltada a este novo público ingressante na educação superior.

Em face desta demanda, a UFFS prevê em seus regramentos a implantação de uma política de apoio ao discente. No Plano de Desenvolvimento Institucional (PDI), os objetivos e as metas da UFFS estão organizados a partir das principais linhas de atuação da universidade desde a sua lei de criação. Tais linhas representam a dimensão estratégica da UFFS, sintetizando as suas responsabilidades institucionais. Dentre as grandes linhas de atuação está a "assistência ao estudante do ensino superior".

De acordo com o Regimento Geral da UFFS, aprovado pelo Conselho Universitário mediante Resolução nº 03/CONSUNI/UFFS/2016, cumpre à Pró-Reitoria de Assuntos Estudantis (PROAE) desta universidade a tarefa de instituir e executar a Política de Permanência da instituição, com a finalidade de ampliar as condições de integração e permanência, promovendo igualdade de condições para o estudante concluir seu curso de graduação. Conforme o Regimento Geral, a esta Pró-Reitoria compete ainda o planejamento da assistência ao acadêmico em situação de vulnerabilidade socioeconômica, a gestão dos programas de auxílios financeiros e a supervisão dos serviços de alimentação e nutrição disponíveis aos estudantes nos Restaurantes Universitários.

Assim, a instituição disponibiliza, a partir de recursos advindos do PNAES, um conjunto de serviços de apoio e modalidades de auxílios que visam apoiar financeiramente o estudante em vulnerabilidade socioeconômica. O Programa de Auxílios Socioeconômicos anualmente abre edital de seleção para estudantes aprovados em análise socioeconômica realizada por Assistente Social. Esta análise é um estudo técnico de caráter socioeconômico desenvolvido a partir de uma entrevista social e da avaliação da documentação entregue pelo estudante. O processo é regrado pela Resolução interna nº 10/2016-CONSUNI/CGAE.

Nos seis campi da UFFS, a unidade administrativa responsável pela execução direta das atividades de assistência estudantil junto aos acadêmicos é o Setor de Assuntos Estudantis (SAE). Compete a este setor em cada campus realizar o acolhimento, suporte e amparo das demandas socioeconômicas e psicopedagógicas dos estudantes. No Campus Realeza, o SAE foi instituído no momento da implantação e início das atividades da instituição em 2010.

As principais ações que o Setor de Assuntos Estudantis desenvolve em atenção ao PNAES concentram-se, em síntese, nos serviços a seguir relacionados: a) acolhimento e orientação aos Avaliação, Campinas; Sorocaba, SP, v. 25, n. 01, p. 5-26, mar. 2020 
acadêmicos; b) realização dos processos de análise socioeconômica; c) gestão do programa de auxílios socioeconômicos; e d) acompanhamento e orientação de estudantes que apresentam demanda de apoio acadêmico. Cumpre destacar, no entanto, que é necessário avançar no que tange à constituição da equipe multidisciplinar para atendimento dos estudantes no Campus Realeza e nos demais campi da instituição.

Atualmente a equipe do campus é composta por uma Assistente social, uma Pedagoga, um Técnico em Assuntos Educacionais e um Assistente em Administração. Desde 2018, o setor não conta com profissional da Psicologia no campus.

É importante destacar também que no período de abrangência deste estudo (2010-2016), na maior parte do tempo o setor não possuiu em seu quadro técnico os profissionais de pedagogia e psicologia, o que comprometia consideravelmente o serviço de apoio, o trabalho interdisciplinar, bem como o acompanhamento pedagógico dos acadêmicos - ação esta que é prevista no Decreto federal $n^{\circ} 7.234 / 2010$ do PNAES, Art $^{\circ} 3^{\circ}$, item IX.

Assim, a execução da Assistência Estudantil na UFFS ocorreu essencialmente pela via da gestão de programas financeiros. A ausência de equipes completas em cada campus e de uma política interna que regulamente, ampare e reconheça os serviços de apoio, imprimiu fragilidade no desenvolvimento do trabalho de assistência estudantil e caracterizou o destaque ao repasse financeiro, levando a compreensão de que este é o principal elemento para garantia da permanência e conclusão de curso dos estudantes.

Em 2016 o Campus Realeza atendeu 313 (trezentos e treze) acadêmicos pelo Programa de Auxílios Socioeconômicos, de um total de 788 (setecentos e oitenta e oito) estudantes com matrícula ativa no mesmo ano, ou seja, 39,7\% dos estudantes do Campus participaram do referido programa.

É salutar fazer alusão também a outro tema de extrema relevância quando tratamos de políticas sociais, e não seria diferente neste caso da Assistência estudantil. Compete-nos falar a respeito da avaliação das ações executadas em atendimento ao PNAES. Sobre este aspecto identificamos que apesar dos indicativos que constam no Decreto federal $\mathrm{n}^{\mathbf{0}}$ 7.234/2010 orientando que as IFES devem fixar mecanismos de acompanhamento e avaliação dos programas - na UFFS identificamos que não se realizou até o ano de 2016 nenhum estudo ou diagnóstico da permanência e desempenho dos estudantes atendidos pela assistência estudantil ou mesmo um 
acompanhamento para analisar o andamento do Programa de Auxílios no decorrer do tempo e seus resultados.

Essa conjuntura trouxe o interesse de investigar a temática no Campus Realeza por meio de um estudo de caso, a fim de analisar se a instituição tem conseguido, para além do acesso, garantir também a permanência e a conclusão de curso deste público inserido nos programas de assistência decorrentes do PNAES, cujo objetivo é propriamente viabilizar a igualdade de oportunidades, contribuir para a melhoria do desempenho acadêmico e agir, de maneira preventiva, nas situações de retenção e evasão. ${ }^{5}$

Para responder a pergunta que move a pesquisa, analisamos os documentos internos da Universidade como relatórios, editais e históricos escolares. Os dados do universo de participantes da Assistência estudantil atendidos pelos programas de auxílios financeiros no Campus Realeza foram pesquisados, totalizando 572 (quinhentos e setenta e dois) estudantes que foram contemplados entre 2010 e 2016.

A coleta dos dados dos históricos escolares dos alunos assistidos e a consulta em editais e registros internos foi realizada nos meses de outubro e novembro de 2016. A organização dos dados no instrumento que elaboramos em formato de planilha eletrônica especificamente para a tabulação levou cerca de quatro meses. Após a conclusão dessa etapa inicial pudemos iniciar efetivamente a análise de todo o material coletado. Com os dados organizados e tabulados foi possível realizar o tratamento estatístico, mediante o uso de fórmulas e cruzamentos de informações.

Na pesquisa analisamos os índices de permanência e conclusão de curso dos estudantes com vulnerabilidade socioeconômica inscritos nos programas de assistência estudantil no Campus Realeza-PR, pois, conforme apontam os estudos realizados pelo FONAPRACE (ANDIFES, 2007), este é o público que efetivamente apresenta maior propensão à evasão e retenção dadas as suas dificuldades socioeconômicas.

Desse modo, analisamos os dados acadêmicos dos universitários inseridos nos programas do Campus no período delimitado de sete anos. Acadêmicos inscritos no programa de auxílios por apenas um semestre, bem como aqueles que participaram continuadamente ao longo dos anos, tiveram seus dados analisados. Observamos a trajetória particular de cada acadêmico no que se

5 A realização desta pesquisa foi aprovada pelo Comitê de Ética em Pesquisa com Seres Humanos - CEP da Universidade Estadual do Oeste do Paraná em 22 de setembro de 2016. 
refere: a) se esteve inserido ou não nos referidos programas em cada ano (2010 a 2016); b) sua trajetória acadêmica (matrícula ativa, evadido, retido, graduado) e desempenho; c) perfil de cada sujeito (sexo, idade, naturalidade). Todas essas informações foram analisadas e tabuladas. $\mathrm{Na}$ sequência, realizamos o tratamento estatístico dos dados pesquisados a fim de sistematizar as informações e elaborar gráficos para facilitar a compreensão e análise dos resultados.

A pesquisa demonstrou que a maior parte dos estudantes atendidos é composta por mulheres, sendo $75,4 \%$ do total de contemplados, enquanto que o percentual de homens é de 24,6\%. Com relação à faixa etária, observou-se que no final do ano de 2016 (momento do levantamento dos dados) a maioria possuía entre 21 e 25 anos, correspondendo a 59,8\% do total de contemplados, seguido por $15,2 \%$ com menos de 20 anos, $15,9 \%$ possuía entre 26 e 30 anos e $9 \%$ tinha acima de 30 anos de idade. No que se refere à naturalidade dos participantes, identificamos que a maioria é da Região Sul do país, correspondendo a 91,4\% dos contemplados, dos quais 78,5\% são do Estado do Paraná.

Em nosso estudo analisamos também a forma mais recorrente de ingresso na Universidade entre os participantes da pesquisa. Identificamos que quase todo o público pesquisado ingressou via ENEM, totalizando 92,5\% dos acadêmicos que acessaram a vaga por esta modalidade. Verificamos que quatro estudantes ingressaram por meio da modalidade de "retorno de alunoabandono". Estes alunos já haviam desistido do curso em outra ocasião e retornaram após algum tempo. Da mesma forma, vinte estudantes são da modalidade "transferência interna", ou seja, desistiram do primeiro curso em que ingressaram para realizar outro curso na instituição.

A investigação realizada apontou ainda que do total de 572 (quinhentos e setenta e dois) contemplados durante o período analisado, 149 (cento e quarenta e nove) concluíram a graduação, o que representa $26 \%$ do total dos acadêmicos atendidos pela Assistência estudantil. Verificamos que efetivamente já estavam no tempo regular para conclusão (ou seja, estavam em vias de colar grau no final de 2016) os acadêmicos que ingressaram em 2010 e em 2011, os quais somavam 227 (duzentos e vinte e sete) estudantes. Isso significa que $65,6 \%$ concluíram o curso (149) e 34,4\% ficaram retidos ou são desistentes (78).

Os dados demonstram também que 15 (quinze) alunos permaneceram por seis anos no programa de assistência e 1 (um) por sete anos. A maioria (noventa e três alunos) usufruiu de assistência financeira por no máximo quatro anos, ou seja, isto representa 62,4\% dos concluintes que participaram do programa por apenas uma parte do seu período de graduação. 
Analisando em quais cursos os concluintes se graduaram, verificamos que 52 (cinquenta e dois) estudantes assistidos eram de Nutrição; seguido por Letras (27); Medicina Veterinária (22); Ciências Biológicas (19); Química (14); Ciências Naturais ${ }^{6}$ (10) e Física (5). Chama a atenção o fato de que os dois cursos de Bacharelado somam sozinhos metade dos concluintes. Isso demonstra, por outro lado, que a taxa de conclusão nas Licenciaturas foi menor, já que temos cinco cursos de formação de docentes.

Por meio da pesquisa documental, identificamos ainda que do total de contemplados durante o período analisado, 126 (cento e vinte e seis) evadiram, o que representa $22 \%$ do total dos acadêmicos atendidos pela Assistência estudantil - número um pouco inferior ao quantitativo de concluintes. É importante destacar que o conceito de evasão utilizado nesta pesquisa foi o de Pereira (1995), que a define como situação em que o aluno deixa a universidade sem concluir nenhum curso. Portanto, na categoria de evadido compreendemos os alunos que apresentam condição de matrícula cancelada (não renovou sua matrícula na instituição), aluno desistente (formalizou desistência do curso) e aluno transferido (estudante se desligou para cursar outra graduação externa).

Em síntese, constatamos que do total de estudantes inseridos no programa de assistência estudantil no Campus Realeza ao longo do período de sete anos, 149 (26\%) concluíram a graduação e $126(22 \%)$ evadiram. Mantém matrícula ativa 278 acadêmicos (48,6\%), apenas 9 estão com a matrícula trancada $(1,6 \%)$ e 10 solicitaram transferência interna para outro curso do Campus Realeza $(1,7 \%)$. O gráfico apresentado a seguir ilustra essas informações.

\footnotetext{
${ }^{6}$ O curso de Licenciatura em Ciências Naturais deixou de ser ofertado em 2013. Em seu lugar foram criadas outras três licenciaturas específicas: Ciências Biológicas, Física e Química.
} 


\section{Gráfico 1 - Número de assistidos e situação de matrícula em 2016}

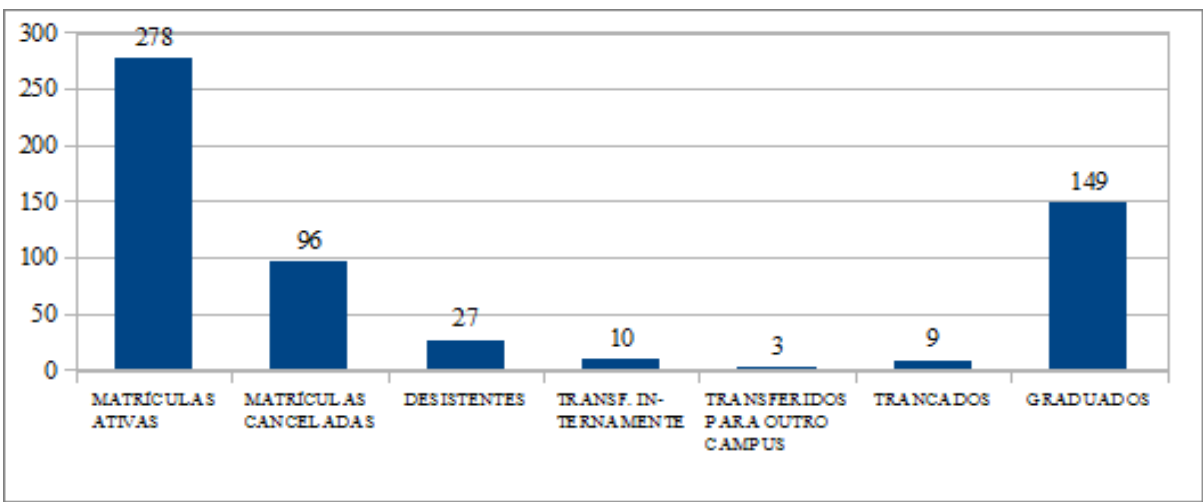

Fonte: Elaborado pelos autores com base nos dados da pesquisa (2016).

Outro dado relevante identificado durante a pesquisa foram as porcentagens de retenção entre os acadêmicos assistidos. Chama atenção a quantidade de estudantes que estão com matrícula ativa, porém apresentam reprovação em três ou mais disciplinas específicas do seu curso, o que leva ao acréscimo de mais um semestre a ser cursado para integralizar a graduação, aumentando assim o tempo de permanência do acadêmico na universidade. O gráfico 2, abaixo, demonstra essa situação.

\section{Gráfico 2 - Número de estudantes assistidos que apresentam retenção}

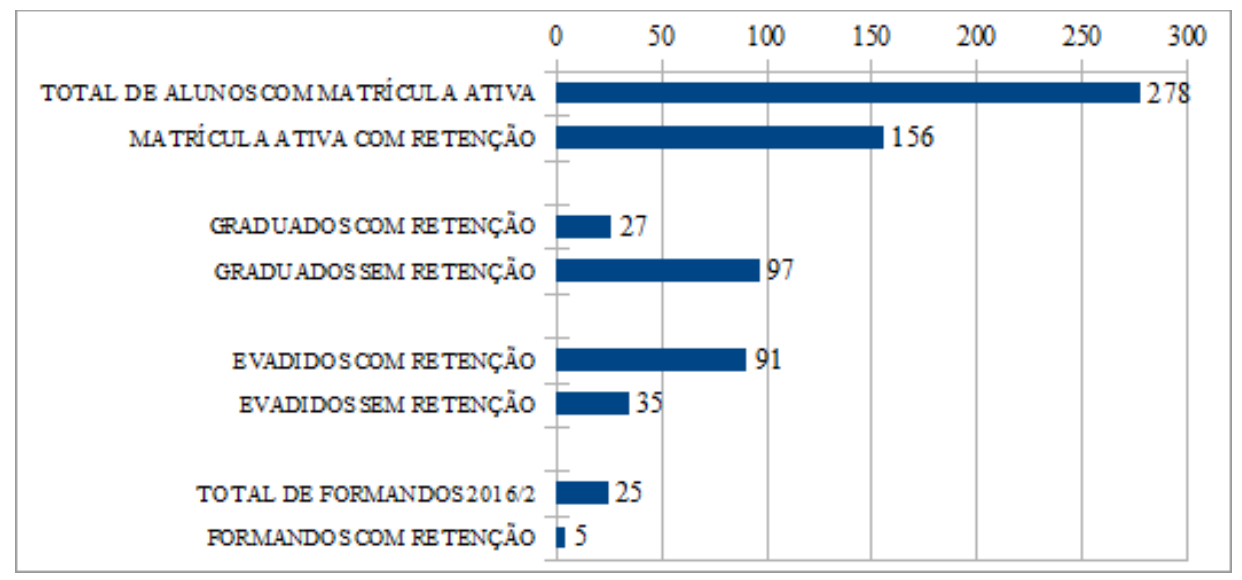

Fonte: Elaborado pelos autores com base nos dados da pesquisa (2016). 
A investigação demonstra, portanto, que $56 \%$ dos estudantes assistidos que permanecem com matrícula ativa no Campus apresentam reprovações que levam à retenção no curso, ampliando seu tempo de permanência na instituição. Entre os estudantes que evadiram a taxa de retenção também é alta. Dos 126 (cento e vinte e seis) acadêmicos evadidos 72,2\% apresentavam reprovações que aumentariam seu tempo de formação em pelo menos um semestre além do tempo regular do curso. Esse fato pode indicar que as dificuldades acadêmicas destes estudantes influenciaram também na desistência do curso. Várias pesquisas inclusive apontam que a incidência de reprovações tem relação direta com a evasão.

Constatamos que um número significativo do universo de participantes dos programas de Assistência estudantil do Campus Realeza permanece vinculado à instituição (278 acadêmicos). Assim, se somados os índices de permanência $(48,6 \%)$ e conclusão de curso (26\%), podemos constatar que os objetivos do Programa Nacional de Assistência Estudantil-PNAES estão sendo alcançados por $74,6 \%$ dos estudantes assistidos. Porém, estes resultados evidenciados por meio da análise documental da trajetória de cada estudante atendido no Campus trazem a compreensão de que os objetivos elencados pelo PNAES e o Programa de Auxílios Socioeconômicos da UFFS têm sido alcançados parcialmente. Pois, o índice de retenção entre os que permanecem é alto, o que demonstra que muitos estudantes apresentam dificuldades em algumas disciplinas e necessitam de suporte e apoio (não apenas financeiro) para a melhoria do desempenho acadêmico. Isso indica que a UFFS precisa de fato incidir sobre as questões relacionadas aos processos pedagógicos e de ensino-aprendizagem, bem como sobre outras demandas e dificuldades apresentadas pelo corpo discente que possam prejudicar seu desempenho e a qualidade do processo formativo.

Em suma, observamos ao longo da nossa pesquisa que o fenômeno da retenção e evasão está presente em muitas IES brasileiras, isso indica um paradoxo: de um lado, políticas de acesso inovadoras, e, de outro, percentuais significativos de abandono e insucesso. Trata-se, portanto, de uma realidade social bastante complexa. A conjuntura que envolve toda a política de educação nacional, desde o ensino básico ao ensino superior carece de investimentos e melhoria nos processos educacionais. Fica evidente também a urgência da implantação de políticas efetivas para que não ocorram novos processos de exclusão após o ingresso desses jovens nas universidades. 


\title{
4 Considerações finais
}

A compreensão da educação em nossa sociedade exige que se recuperem informações sobre a dinâmica social onde os processos educativos se materializam e adquirem sentidos. É necessário apreender a relação entre as determinações históricas do contexto no qual tais políticas são implementadas, pois o sistema educacional sofre influência direta destas relações. Tais condicionantes interferem diretamente nas políticas, a exemplo do próprio REUNI.

Há que se questionar, diante dessa conjuntura, se as políticas públicas de acesso estão assegurando, de modo efetivo, o exercício do direito à educação superior. Os estudos de Dias Sobrinho (2010), indicam que a vulnerabilidade da maioria da população brasileira constitui um dos grandes obstáculos para a "democratização" da educação superior. O autor ressalta as contribuições das políticas de expansão da educação superior, mas aponta também limites diante do quadro estrutural de desigualdade social que o Brasil apresenta. Dias Sobrinho alerta que,

\begin{abstract}
Por mais benéficas e necessárias que sejam as políticas de "democratização" da educação superior, por via de ampliação de matrículas e ações afirmativas de inclusão social, apresentam sérios limites que não serão transpostos em curto espaço de tempo. Muito positivo é o fato de que elas contribuem para uma mudança de cultura contrária à permanência perversa do elitismo e do racismo e favorável ao abrandamento das assimetrias sociais (DIAS SOBRINHO, 2010, p. 1.237).
\end{abstract}

O compromisso assumido pela UFFS de ser uma Universidade pública e popular, aliado à sua política de ingresso, tem proporcionado que mais de $90 \%$ dos estudantes ingressantes sejam oriundos do ensino médio público. Porém, essa mudança de paradigma em relação à universidade tradicional, ao mesmo tempo em que permite o acesso e a inclusão de estudantes de segmentos da classe trabalhadora e outros historicamente excluídos da universidade pública, também aponta vários desafios à permanência e conclusão do curso superior.

Os estudantes das camadas populares trazem consigo as contradições e fragilidades que são reflexo de sua origem social e situação socioeconômica e estes fatores influenciarão a trajetória do jovem pela educação superior. Cabe, nesse contexto, citar um importante alerta feito por Mészáros (2008, p. 11), segundo o qual

O simples acesso à escola é condição necessária, mas não suficiente para tirar das sombras do esquecimento social milhões de pessoas cuja existência só é reconhecida nos quadros estatísticos. E que o deslocamento do processo de exclusão educacional não se dá mais 
principalmente na questão do acesso à escola, mas sim, dentro dela (MÉSZÁROS, 2008, p. 11).

Nessa mesma linha, estudos de Bourdieu (2002) apontam que a estrutura da sociedade é como um sistema determinado tanto pelas relações materiais e/ou econômicas, como pelas relações simbólicas e/ou culturais entre os indivíduos. O autor entende que a herança cultural do sujeito é responsável pelas diferenças na experiência escolar e nas taxas de êxito. Acrescenta que o passado escolar e o tipo de escola à qual se teve acesso: “[...] comprometem muito fortemente as oportunidades de atingir tal ou tal ramo de ensino superior e de nele triunfar. Em síntese, as cartas são jogadas muito cedo" (BOURDIEU, 2002, p. 52). O trecho a seguir expressa fatidicamente a opinião do autor.

\begin{abstract}
Com efeito, para que sejam favorecidos os mais favorecidos e desfavorecidos os mais desfavorecidos, é necessário e suficiente que a escola ignore, no âmbito dos conteúdos que transmite, dos métodos e técnicas de transmissão e dos critérios de avaliação, as desigualdades culturais entre as diferentes classes sociais. Em outras palavras, tratando todos os educandos, por mais desigual que sejam eles de fato, como iguais em direitos e deveres, o sistema escolar é levado a dar sua sanção às desigualdades iniciais diante da cultura (BOURDIEU, 2002, p. 53).
\end{abstract}

Nesse sentido, urge a necessidade de aprofundar o debate nas Universidades a respeito dos processos pedagógicos, do fenômeno das reprovações, da retenção e evasão, do desempenho acadêmico e o chamado "sucesso escolar", do contrário, teremos políticas de acesso bastante inclusivas e inovadoras, mas por outro lado, altas taxas de abandono, vagas ociosas e a possibilidade de fracasso da proposta de democratização da educação superior.

Fica evidenciado também que a assistência estudantil, implementada essencialmente pela via do auxílio financeiro, não apresenta condições suficientes para a atenção às diferentes dificuldades apresentadas pelo corpo discente. A questão econômica e o atendimento às necessidades básicas de alimentação, moradia, transporte, constituem apenas um aspecto da vida universitária.

É necessário reconhecer que o conceito de Assistência Estudantil ainda carece de uma definição mais clara. Em muitas universidades as principais ações são voltadas ao repasse de bolsas e auxílios para atendimento das necessidades básicas de subsistência dos acadêmicos que apresentam vulnerabilidade socioeconômica. Entretanto, a partir dos estudos realizados, concluímos que para garantir a permanência e o êxito na formação, a assistência estudantil deve Avaliação, Campinas; Sorocaba, SP, v. 25, n. 01, p. 5-26, mar. 2020 
observar os diversos aspectos da vida acadêmica de todos os estudantes: socioeconômicos, apoio social (transporte, alimentação, saúde, moradia, creche), desempenho acadêmico (orientação nos processos de ensino-aprendizagem, inclusão digital, bibliotecas, ensino de línguas, bolsas e estágios remunerados), acompanhamento psicopedagógico, acesso à cultura e lazer (manifestações artísticas, esporte) e assuntos da juventude (prevenção de risco e debates de interesse dos discentes).

Por fim, é de suma importância mencionar que os ajustes orçamentários realizados diante do contexto do Estado neoliberal afetam sobremaneira a educação brasileira. Temos de um lado a crescente demanda dos estudantes pela assistência estudantil em face da ampliação do acesso ao ensino superior para as camadas populares, e por outro lado não há o devido aporte orçamentário para as Universidades. Os recursos do PNAES que são repassados às universidades não atendem a crescente demanda discente. Diante dessa realidade fica a questão: Como serão pagos os custos gerados pela expansão do ensino superior diante das constantes instabilidades no orçamento e o contexto de austeridade aplicado às políticas sociais?

Que o futuro nos traga dias melhores e a capacidade de construir a Universidade que está nos nossos corações, nas nossas mentes e nas necessidades do povo brasileiro. (Florestan Fernandes)

\section{Referências}

ANDIFES. Plano Nacional de Assistência Estudantil. Fórum Nacional de Pró-Reitores de Assuntos Comunitários e Estudantis (org.). 2007. 20 p. Disponível em:

http://www.andifes.org.br/plano-nacional-de-assistencia-estudantil-da-andifes/. Acesso em: 06 dez. 2016.

ANDIFES. Revista Comemorativa 25 anos do FONAPRACE: histórias, memórias e múltiplos olhares. Fórum Nacional de Pró-Reitores de Assuntos Comunitários e Estudantis (org.).

Coordenação: Andifes, UFU, PROEX, 2012.

BOURDIEU, Pierre. A escola conservadora: as desigualdades frente à escola e à cultura. In: NOGUEIRA, Maria Alice; CATANI, Afrânio Mendes (orgs.). Escritos de educação. 4. ed. Petrópolis: Vozes, 2002. p. 39-64.

BRASIL. Decreto $\mathbf{n}^{\circ} \mathbf{6 . 0 9 6}$, de 24 de abril de 2007. Institui o Programa de Apoio a Planos de Reestruturação e Expansão das Universidades Federais - REUNI. Brasília, 2007. Disponível em: 
http://www.planalto.gov.br/ccivil_03/_ato2007-2010/2007/decreto/d6096.htm. Acesso em: 28 mar. 2016.

BRASIL. Decreto n ${ }^{0}$ 7.234, de 19 de julho de 2010. Dispõe sobre o Programa Nacional de Assistência Estudantil -PNAES. Brasília, 2010. Disponível em: http://www.planalto.gov.br/ccivil_03/_Ato2007-2010/2010/Decreto/D7234.htm. Acesso em: 18 jun. 2016.

BRASIL. Portaria Normativa $\mathbf{N}^{\mathbf{0}}$ 39, de 12 de Dezembro de 2007. Institui o Programa Nacional de Assistência Estudantil - PNAES. Brasília, 2007a. Disponível em: http://portal.mec.gov.br/arquivos/pdf/portaria_pnaes.pdf. Acesso em: 18 jun. 2016.

BRASIL. INSTITUTO BRASILEIRO DE GEOGRAFIA E ESTATÍSTICA. Síntese de Indicadores Sociais: uma análise das condições de vida da população brasileira 2014. Estudos \& Pesquisas. Informação Demográfica e Socioeconômica, n. 34, Rio de Janeiro, 2014.

BRASIL. INSTITUTO DE PESQUISA ECONÔMICA APLICADA - IPEA. Políticas sociais acompanhamento e análise, v. 1, Brasília: IPEA, 2014a.

BRASIL. MINISTÉRIO DA EDUCAÇÃO. Relatório. Programa de apoio a planos de reestruturação e Expansão das Universidades Federais. 2008. Disponível em http://reuni.mec.gov.br. Acesso em: 26 mar. 2016. FERNANDES, Florestan. Universidade brasileira: reforma ou revolução? São Paulo: AlfaÔmega, 1975.

DIAS SOBRINHO, José. Democratização, qualidade e crise da educação superior: faces da exclusão e limites da inclusão. Educação \& Sociedade, Campinas, v. 31, n. 113, p. 1.223-1.245, out./dez. 2010.

KOWALSKI, Aline Viero. Os (des)caminhos da política de assistência estudantil e o desafio na garantia de direitos. 2012. 180f. Tese (Doutorado em Serviço Social) - Faculdade de Serviço social, Pontifícia Universidade Católica do Rio Grande Do Sul, Porto Alegre, 2012. Disponível em: http://repositorio.pucrs.br/dspace/handle/10923/5137. Acesso em: 12 mar. 2016.

MÉSZÁROS, Isteván. A educação para além do capital. 2. ed. São Paulo: Boitempo, 2008.

OLIVEIRA, Dalila Andrade. As políticas educacionais no governo Lula: rupturas e permanências. Revista Brasileira de Política e Administração da Educação, Porto Alegre, v. 25, n. 2, p. 197-209, maio/ago. 2009. Disponível em: http://seer.ufrgs.br/index.php/rbpae/article/view/19491/11317. Acesso em: 12 dez. 2016. PEREIRA, José Tomaz Vieira. Uma contribuição para o entendimento da evasão: um estudo de caso. São Paulo: UNICAMP, 1995.

PEREIRA, Thiago Ingrassia. Classes populares na universidade pública brasileira e suas contradições: a experiência do Alto Uruguai Gaúcho. Cutitiba: CRV, 2015. 
ROMÃO, José Eustáquio; LOSS, Adriana Salete. A universidade popular no Brasil. Foro de Educación, Salamanca, Espanha, v. 12, n. 16, p. 141-168, jan.jun. 2014. Disponível em: https://forodeeducacion.com/ojs/index.php/fde/article/view/306/pdf_30. Acesso em: $21 \mathrm{fev}$. 2016.

ROTTA, Edemar; VITCEL, Marlise Sozio; ANDRIOLI, Antônio Inácio. A Universidade Federal da Fronteira Sul e a sua experiência de inclusão por meio da instituição das cotas sociais. In: LUFT, Hedi Maria; FALKEMBACH, Maria; CASAES, Juliana Borba de. (org.). Freire na agenda da educação: inclusão e emancipação - educação de jovens e adultos. Ijuí: Ed. Unijuí, 2012. v. 2

UNIVERSIDADE FEDERAL DA FRONTEIRA SUL. Estudantes são das regiões dos campi. 2010. [matéria online publicada em 24 de fevereiro de 2010]. Disponível em: https://www.uffs.edu.br/institucional/reitoria/diretoria_de_comunicacao/noticias/estudantes-saodas-regioes-dos-campi. Acesso em: 20 fev. 2017.

UNIVERSIDADE FEDERAL DA FRONTEIRA SUL. Carta de Serviços ao Cidadão. Santa Catarina, 2013. 19 p. Disponível em:

https://www.uffs.edu.br/institucional/a_uffs/carta_de_servicos_ao_cidadao. Acesso em: 20 fev. 2017.

UNIVERSIDADE FEDERAL DA FRONTEIRA SUL. Apresentação. 2017. Disponível em: https://www.uffs.edu.br/institucional/a_uffs/a_instituicao/apresentacao. Acesso em: 20 fev. 2017.

UNIVERSIDADE FEDERAL DA FRONTEIRA SUL. Sistema de Gestão Acadêmica. 2017a. Disponível em: http://sga.uffs.edu.br. Acesso em: 20 fev. 2017. 